Marquette University

e-Publications@Marquette

Economics Faculty Research and Publications

Economics, Department of

$1-1-2015$

\title{
Stratification Economics and Identity Economics
}

John B. Davis

Marquette University, john.davis@marquette.edu

Accepted version. Cambridge Journal of Economics, Vol. 39, No. 5 (2015): 1215-1229. DOI. (C) 2015

Oxford University Press. Used with permission. 
Forthcoming Cambridge Journal of Economics

\title{
Stratification economics with identity economics ${ }^{1}$
}

\author{
John B. Davis \\ Marquette University and University of Amsterdam
}

\begin{abstract}
Stratification economics represents an important new approach devoted to explaining economic inequality in terms of how social groups are separated or stratified along economic lines. This paper combines stratification economics with identity economics to address complications that the phenomenon of intersectionality - people having multiple social group identities - creates for stratification economics. It distinguishes two types of social identities recognized by social psychologists, categorical and relational social identities, and uses this distinction to explain how individuals' personal identities, understood as ordered sets of social identities, can be seen to be both socially and self-constructed. Individuals order and rank their categorical social identities according to weights they assign to them in interactive social settings in which their role-based relational social identities combine different categorical social identities. Recent research in social psychology in the stigma identity threat literature is then reviewed to distinguish two different ways in which individuals respond to others' stigmatization of their social groups in interactive settings. The paper argues that individuals respond to stigma by assigning weights to their categorical social group identities in ways that reflect both functional power relationships and stigmatization in a way that on balance tend to reinforce social stratification.
\end{abstract}

Keywords: stratification, social identity, intersectionality, personal identity, stigma, identity-threat JEL codes: Z13, D74, A12

\footnotetext{
${ }^{1}$ Presented at: Third International Research Conference of the International Confederation for Associations for Pluralism in Economics, Amherst, MA, 11-13 November, 2011; Cercle d'épistémologie économique, Université de Paris I Panthéon-Sorbonne, March 8, 2012; World Congress of Social Economics, Glasgow, June 21, 2012. The author gratefully acknowledges comments by Beatrice Boulu-Reshef, William Darity, Jr., Zohreh Emami, Alex Haslum, Miriam Teschl, attendees at its presentations above, and the referees of this journal.
} 


\section{Combining stratification economics and identity economics}

The focus of stratification economics, an emergent subfield in economics (now included under JEL classification Z13), is group-based inequality and the social economic hierarchies associated with individuals' identification with social groups, allegiance to which is manifested in asymmetries between their pro-own-group and anti-other-group behaviors (Darity, 2003, 2005, 2009; Darity and Deshpande, 2003; Darity, Mason, and Stewart, 2010; Goldsmith, Hamilton, and Darity, 2006; Mason, 2007; Stewart, 2008a, 2008b). Individuals are first and foremost members of social groups, and their identification with those groups causes their behavior to reflect the interests of those social groups. For example, in the Darity-Mason-Stewart analysis, individuals' personal identities are endogenous to their racial social group identities, and their behaviors reflect the norms of their racial group (Darity, Mason, Stewart, 2006). Individuals act as representative agents of social groups, not as isolated atomistic agents, social groups are the real economic agents, and income and wealth differences in society are explained in terms of intergroup competition and conflict. The economy is accordingly explained using a social ontology approach in which society is structured and organized by wealth and social group relationships rather than explained by using a standard individualist approach which suppresses these differences.

This analysis works most straightforwardly in circumstances in which social group polarization is high and social group identification is nearly unique, meaning that individuals can basically be seen as being of a single type because they identify with only one of a few main social groups, the membership of which is then essentially homogeneous in virtue of being based on that type alone. Societies and circumstances that are characterized by strong racial/ethnic or class division reflect this type of case. Things are often more complicated, however, because in many settings people identify with more than one social group, for example, by race, class, religion, and gender. Then individuals are made up of multiple types - a phenomenon referred to as intersectionality (Crenshaw, 1989; Meyers, 2000) - and can no longer be described simply as representative agents of one single social group. Rather they are then identified by their particular collections of social group overlaps or intersections they have. Further, whereas in the single representative agent type case the individual's identification with the group is by definition unconflicted, in the multiple social identity type case identification with conflicting social groups creates conflict for the individual. 
This makes social conflict a personal conflict as well as an inter-group conflict, and provides a way of expanding the behavioral analysis of individuals in stratification economics.

Intersectionality implies that social groups have heterogeneous rather than homogeneous memberships. For example, in terms of race and gender, women of different races can identify with women as a social group, so that there is heterogeneity within women as a social group, while women and men can identify with the same racial social groups, so that there is heterogeneity within racial groups. Thus in contrast to the basic stratification model, social groups are not completely polarized, and group member behavior can no longer be explained as pro-own-group and anti-other-group. ${ }^{2}$ Individuals can have pro-own-group allegiances to different social groups that on average practice anti-other group behavior toward one another, and individuals can even find themselves being anti-own group in circumstances when their other group loyalties are preeminent. Thus the sharp dividing line between pro-own-group and anti-other-group behavior is blurred, and intragroup conflict interacts with intergroup conflict. The issue then becomes what degrees of commitment do individuals have to their different social group identities, and what factors influence these degrees of commitment. This paper examines this issue in terms of how individuals prioritize and order their social identities according to changing social circumstances.

This approach, however, creates a problem for stratification economics. Stratification economics aims to explain group-based inequality and the intergroup conflict associated with individuals' exclusive identification with opposed social groups. In contrast, intersectionality suggests a view of the world in which social stratification and group-based inequality are offset or moderated by individuals' cross-cutting social group identities, which might imply that social conflict decreases in a world made up of increasingly heterogeneous social groups. Against this, there is considerable evidence that social group hierarchies in income and wealth are highly enduring in contemporary societies. How should the field of stratification economics proceed, then, in explaining social stratification in a multi-polar group world exhibiting intersectionality?

The answer developed here combines stratification economics and an identity economics approach which defines individuals as collections of social identities. The paper assumes that the world is socially structured in such ways that people 'find' they possess certain social group identities, and

\footnotetext{
2 The asymmetry in pro-own-group and anti-other-group behavior was originally demonstrated by Tajfel et al. (1971), and is the foundation of social psychology's social identity approach and John Turner's development of it as self-categorization theory (cf. Turner, 1975).
} 
argues: (1) that people are motivated to order and rank their different social group identities when social conflict between different social groups of which they are members creates personal conflict for them, and (2) that this occurs in ways that tend to reinforce rather than weaken social stratification and social group hierarchy. ${ }^{3}$ The paper develops this argument by employing social psychology research on how social stigma targets individuals perceived by stigmatizers to be representative members of social groups. In response to such targeting individuals re-evaluate the weights they place on their different social identities. The argument thus develops a behavioral analysis in which social conflict generates personal conflict, and in which how individuals order their different social identities changes their personal identities as collections of social identities.

The paper builds on social psychology's distinction between two main types of social identity: categorical and relational. Relational social identities correspond to interconnected social roles and categorical social identities correspond to broad social aggregates or groups of people who share some characteristic. Since social roles also link people who are members of broad social groups, relational social identities associated with social roles link different categorical social identities associated with membership in broad social groups. The argument in the paper is that individuals are directly influential in determining how their social roles play out, this then influences their relational social identities, and this then influences the way they regard their categorical social identities. Nonetheless, as social identities are largely socially constructed, people's selfconstruction of their identities in terms of their social identity profiles is inherently constrained. This approach has the general aim of making social group conflict intrinsic to personal identity, thus making the conception of individuals social by making social relationships associated with social groups and the conflict between them fundamental to what individuals are. 4

Section 2 briefly opens with this last point, arguing that a social conception of individuals, here as collections of social identities, allows us to advance our general understanding of individual behavior by treating social conflict and personal conflict as related and mutually determining. Section 3 uses the social psychology literature on social identity to differentiate categorical social

\footnotetext{
${ }^{3}$ Note that critical realists similarly emphasize that the world is socially structured. Consider the following from Lawson: "once a structured ontology is recognized we can see that multiplicity in the course of actuality remains coherent with a degree of uniformity at the level of underlying causes or structure" (Lawson, 1999, p. 48).

${ }^{4}$ This approach contrasts with that of Akerlof and Kranton (2000) who also apply social psychology's social identity approach to the explanation of individual behavior, but retain the atomistic utility maximization conception of the individual.
} 
group identities and relational social identities, and argues that the social construction of individuals' personal identities operates primarily through their categorical social group identities, while individuals' self-construction of their personal identities operates primarily through their interpretation of their relational social identities and associated categorical social identities. Section 4 turns to the literature on stigmatization of social identities and social psychology's 'identity threat' explanation of stigma, distinguishes the two main opposed ways in which recent empirical research on social stigma has found that individuals respond to identity threats, and then links this literature to the question of how individuals order their social identities and construct their personal identities out of their social identities. Section 5 shows that when we take into account a few basic characteristics of a stratified social economic world, and recognize the role that individualist social ontologies play in the representation of this world, both of these two types of responses to stigmatization in an identity construction process tend to reinforce rather than weaken social stratification and the hierarchical relationships between social groups. Section 6 concludes with brief remarks regarding social policy strategies for addressing both the ethical and economic failings of a stratified social economic world.

\section{Social conceptions of individuals}

Recent mainstream economics offers a counterfeit social conception of individuals in suggesting that people can be motivated both 'intrinsically' by private concerns and 'extrinsically' by social concerns (e.g., Bénabou, and Tirole, 2003). Is it plausible to say that the utility maximization model of the atomistic individual can be used to explain extrinsically motivated social behavior because utility functions could include a range of other-regarding concerns, all under the utility maximizing umbrella of self-regardingness? The problem with proceeding in this way is that adding social motives to utility functions is an entirely ad hoc step without any theoretical basis in the utility function itself. Indeed, the idea of a preference per se tells us nothing about the content of preferences, so that not only is there nothing in preference analysis to justify the claim that some preferences are 'social' or other-regarding, but the fact that preferences are necessarily always the individual's own preferences suggests just the opposite. The standard reasoning seems to be that if critics of mainstream economics fault it for ignoring evidence regarding the social character of individual behavior, the easy solution is to simply say that the utility maximizing individual was always (at least some of the time) socially motivated! The particular advantage of this strategy, 
moreover, is that it is left to the standard theorist to decide how much or whether such motives should be part of the model. That is, whether the theorist regards an agent's preferences as 'social' or not is essentially the individual theorist's own preference!

Another way of treating individuals as social beings compatible with the standard utility function view is to say 'individual' preferences are 'endogenous' or are determined by social factors (Bowles, 1998). Endogenizing preferences has a certain appeal for critics of the standard view because it can be readily agreed that social forces influence people's preferences. But the logic of how social factors act on preferences remains largely heuristic and again basically ad hoc, so that it is quite unclear how, to what degree, or even whether preferences might be socially endogenous. Further, this strategy is actually complementary to the social motives one above because it provides a way of accounting for other-regarding preferences that does not pose a challenge the atomistic individual framework itself. How preferences may have been endogenized is irrelevant to the role they play in utility maximizing behavior as the individual's own preferences (Becker, 1996, p. 4).

The approach here, then, takes an entirely different route to explaining individuals as social by defining them in terms of their social group locations and social identity characteristics rather than by defining them individualistically as collections of preferences. People can be individualized by their particular social group locations or, when we focus on them having multiple social identities, by the particular sets of social identities they possess compared to the particular sets of social identities that other people possess. An advantage of this approach is that, because social motives can be associated with having social identities, social motives are directly (rather than arbitrarily) embedded in individuals when they defined as collections of social identities. A further advantage is that since social groups are regularly in conflict, conflict is made central to how individuals are defined.

Stratification economics employs this social identity-social conflict approach to personal identity because it characterizes individuals as representative agents of conflicting social groups. In the multiple social identities intersectionality case, this also makes it possible to say what kinds of collections of social identities people are, namely collections that can be discordant and unstable. Social psychology's social identity theory also explains personal identity in terms of social conflict since it explains individual behavior through the asymmetry between individuals' pro-own-group and anti-other-group behaviors. When we then emphasize that individuals have multiple social identities, not only must they be explained as being motivated to differentiate appropriate pro- 
own-group and anti-other-group behaviors in intergroup conflicts, but their overlapping social group identifications additionally require that they address intragroup conflicts. In addition, both approaches share a view of the nature of individual motivation, namely, that people are motivated to ameliorate the personal conflicts they experience as a result of social conflicts. Further, since social conflict and personal conflict are connected, both approaches supports the idea that the economic process is a perpetual dynamic lacking any inherent tendency to settle to equilibrium. In section 4, this dynamic is explained in terms of whether members of stigmatized social groups increase or reduce their social identification with stigmatized groups. Social stigmatization is an exercise of social power. Thus the overall approach here makes it possible to address how individuals act in a world of dominated by power relationships and social conflict, contrary to the natural harmony vision of the world implied by the utility maximizing approach to individuals.

How, then, are individuals' personal identities both socially and self-constructed? To answer this question the following section differentiates relational and categorical social identities, and then explains the identity construction process in terms of the different ways in which these two types of social identities relate to individuals.

\section{Personal identity as socially constructed and self-constructed}

Social identity is generally understood as the type of identity people have when they identify with others, where this can be either an identification with particular people with whom one interacts typically directly in certain social role settings (Stets and Burke, 2000), or an identification with people as members of social groups with which one identifies, commonly without knowing most group members (Hogg, Terry, and White, 1995). Social psychologists label the two types of social identities individuals' relational and categorical social identities. There are "(i) those that derive from interpersonal relationships and interdependence with specific others and (ii) those that derive from membership in larger, more impersonal collectives or social categories" (Brewer and Gardner, 1996). Put differently, people have social identities that are "identifications of the self as a certain kind of person" - a role-based identity - or they are social identities involving "identifications of the self with a group or category as a whole" - a collective identity (Thoits and Virsup, 1997, p. 106). Social identities that are relational are so in virtue of a person occupying a specific position in a "relational web" (kinship, friendship, employment, patron-client, team 
member, etc.), and identifying with people who have coordinate social roles and to whom one is connected in that relational setting. Social identities that are categorical are so in virtue of individuals "sharing some categorical attribute" with other like people (race, ethnicity, gender, age, disability, language, class, nationality, sexual orientation, etc.) irrespective of shared relational settings or personal interaction between them, so that the individual socially identifies with another person as a 'like' representative of that shared category (Brubaker and Cooper, 2000, pp. 15ff).

We may summarize this classification by saying that an individual's relational and categorical social identities can be distinguished according to two measures: (a) whether those with whom one identifies are 'like' or 'unlike' oneself, and (b) how personally proximate others are. In the case of categorical social identities individuals are 'like' one another as equally members of a broad class or category, such as a particular ethnicity, but generally have no proximate personal connection. They identify with one another, or are identified with one another by others, in virtue of their shared likeness alone (though sometimes they have personal connections). In contrast, with relational social identities, individuals are 'unlike' one another in virtue of occupying different social roles, and this close role interdependence produces personal proximity. They are personally connected because interdependent roles bring 'unlike' people together (even if they are similar in other respects), and they identify with one another, or are identified accordingly by others, in connection with these roles.

Note, then, that categorical social identities are socially constructed in the sense that they originate in social statistical processes in locations generally distant from the people to whom they are ascribed by people who themselves are generally not members of groups they construct. They are based on social categories (thus the name) created by government agencies, the media, business, popular opinion, and social research that engage in data collection processes which define broad collections, groups, or classes of individuals in terms of certain shared sets of characteristics or likenesses for the purpose of managing information about distinguishable populations of people and for the exercise of social control (cf. Samuels, 1964a, 1964b). Individuals regarded as having 'like' characteristics are thus assigned membership in these categories by the various parties involved in their construction.

Individuals can of course resist their category assignments, and assess the degree to which or whether they believe that the average characteristics which define a particular social group 
category apply to them. For stratification economics, however, the social construction of categorical identity is deeply embedded in inter-group inequality relationships and thus highly resistant to change. Indeed, social categories often function to maintain systems of prejudice which secure dominant social groups' relative position vis-à-vis subordinated social groups (cf. Blumer, 1958). So individuals may contest their social category assignments but are most are constrained in the degree to which they are able to do so. A good example is the evidence that darker skinned Latinos suffer larger discriminatory penalties in U.S. labor markets than lighter skinned Latinos, even if the former self-report their race as white (Frank et al., 2010).

Compare now individuals' categorical social identities with their relational social identities, which are based on differences rather than likenesses, as in the case of two people who identify with one another because they work together in linked but different occupations. Their separate occupations are still associated with the different categorical social identities they each possess, but when their occupations are combined in role settings, their categorical social identities get embedded in their relational social identities. On the one hand, their role labels, taken apart from the relational setting are still simply social categories, and so derive their principal meanings from how they have been socially constructed. On the other hand, their meanings in specific relational settings get tied to how the people who occupy these roles interact and interpret the scope of the social categories involved. This is especially the case when there is disagreement and conflict over the scope and interpretation of roles. That people identify with one another when roles are interdependent does not imply that conflict is absent in relational settings! Accordingly, whereas people have little influence over the social construction of their categorical social identities taken outside of relational contexts, in relational settings people have an immediate arena in which they may be able to influence in some degree how social categories are applied to them. With respect to the two measures used above to distinguish the two types of social identity, individuals have whatever influence they have regarding the social construction of their identities in those circumstances where they have close personal interaction with people who are 'unlike' them.

Thus if individuals' personal identities are said to be the particular sets of social identities they possess, then individuals are involved in the construction of their own personal identities in concrete relational settings out of the socially constructed categories others create for them. In other words, "individuals construct their own identity, but they do not construct their identity just as they please; they do not construct it under circumstances chosen by themselves, but under circumstances encountered, given and transmitted from the past" (Darity, Mason, and Stewart, 
2006, p. 290). ${ }^{5}$ Needless to say, it is an open question how much space individuals may truly have in this regard. In any event, it should be emphasized that since social role relationships and relational social identities generally involve power relationships and social conflict, individuals' personal identities are not only inherently social, but are also often the product of social conflict. Individuals are consequently not atomistic beings, but are beings that make their choices based on the need to manage their conflicting social identities. To explain this further, the next section turns to how these choices involve how people vary the weights they place on their different social identities in response to the stigmatization of social identities.

\section{The stigmatization of social identities and the stigma identity-threat model}

An important factor reinforcing social group stratification and group-based inequality is the stigmatization of social identities. Subordinated social groups are subjected to discrimination and prejudice, and this influences their access to social and economic resources. As a result, their members' well-being is lower than that of individuals from dominant social groups which are not devalued. As for its mechanism, stigma is applied by individuals to other individuals in virtue of the latter's perceived social identities (though it can also be simply directed at groups). When a person is stigmatized, that individual is represented as possessing "some attribute or characteristic that conveys a social identity that is devalued in a particular social context" (Goffman, 1963, p. 505). At the same time, while stigma is applied by individuals to individuals, it should not be said that stigma and prejudice exist simply as "a set of feelings which members of one racial group have toward the members of another racial group" since this fails to recognize "the collective process by which a racial group comes to define and redefine another racial group" (Blumer, 1958, p. 3; cf. Darity, 2009, pp. 803-5). That is, in stratification economics stigmatization and prejudice need to be understood in terms of intergroup dynamics and hierarchical differences in power between social

\footnotetext{
${ }^{5}$ Margaret Archer makes a similar statement in her own analysis of human agency: "we do not make our personal identities under circumstances of our own choosing. Our placement in society rebounded upon us, affecting the persons we become, but also and more forcefully influencing the social identities which we can achieve. Personal and social identity must not be elided, because the former derives from our relations with all three orders of reality, whilst our social selves are defined only in social term" (Archer, 2000, p. 10).
} 
groups, not in an individualistic way as in the neoclassical 'taste for discrimination' approach (Becker, 1957). ${ }^{6}$

On the stigma identity-threat model, then, when stigmatization and prejudice cannot be ignored, they pose an 'identity threat' to the individual where the burdens it creates are perceived as exceeding the individual's coping abilities, which then precipitates action on the part of the individual that tells us how they appraise their threatened identity (Steele, 1997). The stigma identity-threat model has thus been used by social psychologists as a research tool to explain both what produces identity threats and how individuals respond to them (Major and O'Brien, 2005). Here I focus on the two main opposed ways in which individuals have been empirically observed to respond to identity threats associated with their membership in social groups according to social psychology social identity research: individuals further embracing their devalued social identity or distancing themselves from their devalued identity.

There is considerable research and evidence regarding the first, further embracing type of response. Individuals who have had their social identity stigmatized are often observed identifying more closely rather than less closely with their social group in response to perceived prejudice or discrimination (Branscombe, Schmitt, Harvey, 1999). In the social identity model of the individual used here, individuals increase the weight they place on the devalued social identity, increase their identification with those they see to be 'like' themselves in the social group, and make stronger proown-group/anti-other-group distinctions in their behavior. Essentially the greater weight they place on the devalued social identity offsets its social stigma (Branscombe and Jetten, 2009). This is one way of coping with an identity threat.

But there is also considerable research and evidence regarding the second, distancing type of response. In circumstances particularly where individual mobility is significant because boundaries between social groups are relatively permeable, individuals not infrequently take the opportunity to distance themselves from a devalued social group, and decrease their identification with it (Ellemers, van Knippenberg, and Wilke, 1990). The permeability of boundaries between groups depends on many things. Skin color and gender, for example, may appear to involve impermeable boundaries, but there are circumstances in which they simply do not count.

\footnotetext{
${ }^{6}$ Note that the 'taste for discrimination' approach assumes that discrimination and prejudice will 'ultimately' disappear in competitive market systems. On this view, prejudice is purely a personal problem that the market remedies, not one associated with the structural nature of a stratified hierarchical economic system.
} 
Conversely, some characteristics such as family background may seem to create relatively permeable boundaries, yet there are circumstances in which they count significantly. In any event, when individuals distance themselves from stigmatized social groups, they reduce the weight they place on the devalued social identity, see themselves as less 'like' those in the social group who others believe them to be 'like,' and moderate or reverse their pro-own-group/anti-other-group distinctions. Social stigma may still be applied to them if they are seen by others to be members of the devalued social group, but they offset its effects by their lesser identification with the stigmatized social group by feeling they have a low commitment to the devalued group (Ellemers, Spears, and Doosje, 2002). In effect, they cope by supposing the identity threat applies to others, not to them.

In both lines of research, then, individuals' re-weighting of the devalued social identity turns on a judgment of their degree of likeness to other members of the stigmatized group that results in their increasing or decreasing the weight they place on their being 'like' others in that group. That is, their response to stigma and its devaluation of the group is to re-assess the assignment to them of the stigmatized categorical social identity. I argued in the last section that people's categorical social identities are essentially socially constructed, but that in relational settings involving social roles these categorical social identities are combined as relational social identities, and then subject to individual interpretation. What this identity analysis adds to the evidence on stigmatization in social psychology, then, is a way of understanding why people exhibit these two very different kinds of responses to stigmatization that has to do with the dynamics of interaction in social roles. Identity construction occurs in social role settings, because people's direct interaction with one another in them occasions dispute and conflict over the interpretation of their roles and categorical social identities. This tells us that we need to look more closely at how power operates in these role settings, and examine how stigmatization is directed, not towards individuals in certain social groups in general but towards certain individuals in social role contexts in which those engaged in stigmatization have particular power advantages.

For example, consider the case where an employer uses stigma toward an employee on racial or gender grounds in a specific employer-employee setting to improve the employer's advantage over wages, working conditions, etc. In such circumstances assigning stigma is a means of securing or reinforcing an existing power relationship by reinterpreting employer and employee social roles in favor of the former, and is thus a means by which dominant social groups maintain or strengthen their relative position over subordinated social groups. Power has two dimensions: functionality in 
social roles, which are often asymmetrical in influence over shared activities, and power that derives from hierarchies between social groups. Of course individuals who employ stigma with the intent of increasing their power advantages typically possess both functional power advantages and social hierarchical advantages. But the issue here is the response on the part of those who are stigmatized. In terms of social psychology's two observed types of responses, why does an exercise of power cause those targeted to further embrace or turn away from a devalued social identity?

What the social identity social psychology research broadly tells us regarding stigmatization and the dynamics of interaction is that two factors, social context and degree of commitment to a social identity, are key to determining individual response to stigmatization, and that the latter, commitment, seems to depend on some measure of individual mobility understood in terms of how permeable the boundaries are between social groups (Ellemers, Spears, and Doosje, 2002). What more can we thus say about permeability when we focus on social roles? Consider the employeremployee social roles case in a more fine-grained, within-organization employment social context. Suppose also that employees have multiple social identities. In most firms, social hierarchies operate through promotion ladders, and a subordinate's steps up a ladder can be manipulated by superiors' exercise of power through stigmatization and selective favoritism toward the employee's non-firm, non-role categorical social identity, say race or gender. An important concept in social psychology for explaining this is the concept of 'social distance' as in the 'social distance' between steps on a promotion ladder (Haslam, 2004). An advantage of the idea of distance when applied to the idea of promotion ladder is that it is conveniently ambiguous regarding whether individuals on different steps of a promotion ladder are 'like' or 'unlike' one another, and consequently whether the person who steps up a promotion ladder is sufficiently 'like' or 'unlike' the people already there (as in: 'you weren't one of us before, but you are now').

Thus on the one hand, if the social distance between two positions on a ladder is interpreted by organizational superiors as not being large, superiors and subordinates can be almost 'like' one another, despite different categorical social identities such as race and gender and the hierarchical differences between social groups. The next step up in the organizational hierarchy ladder simply gets represented as being not very far. In this social context, individuals may devalue their stigmatized racial or gender identity (e.g., Ellemers, van Knippenberg, and Wilke, 1990) in order to pursue social mobility. They reject likeness to those in the stigmatized categorical social identity as 'subordinate' and may embrace others with different racial or gender social identities as 'like' and 'superior.' They may then give up their previous pro-own-group/anti-other-group race or gender 
behavior, and may even embrace an anti-own group/pro-other group race or gender behavior. Intragroup conflict replaces intergroup conflict.

On the other hand, if the social distance between two positions of individuals on the organizational ladder is interpreted by organizational superiors as being large, then superiors and subordinates are more likely to be represented as 'unlike' one another. In this social context, those down the organizational ladder with a stigmatized racial or gender identity may further embrace their stigmatized racial or gender categorical social identity (Branscombe and Jetten, 2009), may actively embrace its 'subordinate' status, and may pursue an intensified pro-own-group/anti-other-group behavior as a means of coping with the negative effects of stigmatization. Intergroup conflict takes priority over intragroup conflict.

In both cases, individuals self-construct their personal identities out of their collections of socially constructed categorical social identities by interpreting their relational role-based social identities in circumstances where those with social power seek to increase their advantage through stigma. What accordingly determines personal identity in society is partly the choices of individuals, partly the nature of social structure in institutions and organizations as they affect social roles, and partly prevailing practices of prejudice and stigmatization employed by dominant social groups.

Individuals are thus relatively distinct beings whose identities are nonetheless also endogenous to social forces (cf. Darity, Mason, and Stewart, 2006, p. 290). This analysis, however, still leaves unaddressed whether intersectionality thus understood weakens or reinforces social stratification. This is the subject of the following section.

\section{Stigma, identity construction, and the reinforcement of social stratification}

Intersectionality, again, is when individuals are members of multiple social groups and have multiple social identities. Compared to a world in which social groups are highly polarized and individuals are only of one type and are representative agents of single groups, when individuals are members of multiple social groups and have multiple social identities, they may effectively act as representative agents of one social group at one point in time and then act as representative agents of another social group at another time. For example, individuals may move from a racial or ethnic social group identity to a gender social group identity or from a gender to a racial or ethnic 
social group identity. Thus intersectionality introduces individual mobility into stratification analysis, albeit in a manner limited by a society's structure of intergroup inequalities.

Such a world would thus can be said to have three main characteristics: (1) social strata can be ranked in terms of average well-being, with higher strata providing higher levels of average wellbeing than lower strata; (2) social groups are arrayed vertically across strata and are not mobile across strata; (3) there are high, but not insurmountable, barriers to individuals' 'vertical' or upward cross-strata mobility and low barriers to individuals' 'horizontal' or lateral within-strata mobility. The first two characteristics operate in a world of highly polarized social groups. The third characteristic is added to reflect individuals' ability to change their social group representative agent status in a multi-polar social group world, though it is framed in such a way that mobility is still limited by stratification. Nonetheless, the addition of the third characteristic changes the social ontology of stratification economics since it expands its intergroup dynamics to include an individual-group dynamics, though with the latter framed by the former. This has interesting implications for how we interpret individual identity behavior when we recognize that social contexts in which it is at issue, such as the promotion ladders example, are represented in individualistic terms by those who employ stigmatization and prejudice as instruments of social group power.

In the individualistic social ontology of stigmatizers, social hierarchies are absent and the world is ruled by natural scarcity. ${ }^{7}$ Thus they portray promotion ladders as reflecting scarce opportunities available for individual advancement and upward or 'vertical' mobility which, moreover, are clearly represented as being different from the abundant opportunities available for 'horizontal' or lateral, within-strata mobility. Consider again, then, the social psychology concept of social distance in connection with the idea of steps on a hierarchical ladder. In a world of scarcity, the measure of social distance, or how great the separation is between steps on the ladder, must be proportional to the scarce opportunities available for ascending the ladder. That is, the fewer the opportunities, the greater the social distance to the next step up on the ladder. This implies that exit from a stigmatized social identity and the prospect of entry into a non-stigmatized social identity up a ladder can be influenced by unexpected short-run changes in the availability of opportunities for promotion. That is, individual mobility is an exceptional state of affairs. However, creating unexpected short-run opportunities for promotion is precisely the province of stigmatizers in

\footnotetext{
${ }^{7}$ This is of course the world of neoclassical economics.
} 
positions of power. Since stigmatization is an unacknowledged practice in hierarchical systems (on the part of those who wield it!), discrimination can be selectively targeted at some individuals and its absence or favoritism selectively targeted at others as the stigmatizer sees appropriate to the exercise power, with the difference between the opportunities being represented purely in scarcity terms. Social distance in the steps on a promotion ladder is thus a power variable, and one ultimately governed by the structure of hierarchical group relationships.

Accordingly, in terms of the categorical social identities involved, when social distance is reduced temporarily for one set of individuals to whom stigma might otherwise be applied, their interpretation of who they are 'like' is determined by both the possibility of stigma and the framing of their opportunities for individual mobility in scarcity terms. A scarce opportunity, suddenly made temporarily available to the otherwise stigmatized individual, one can argue, changes the perceived permeability of boundaries between social groups. Favored individuals may then distance themselves from their devalued racial or gender social identity, seeing themselves as the rare exceptions who are 'like' those who are 'unlike' them, while others who are not offered these scarce opportunities are more likely re-embrace their devalued identities, seeing themselves as 'like' those who are 'like' them.

In a stratified world, individualistic social ontologies prevail because they reinforce stratification by obscuring the dynamics of intergroup inequality. In an intersectional world, promotion ladders, social distance, stigmatization consequently work to reinforce social stratification rather than weaken it, so that people having multiple social identities fails to offset intergroup inequality. The argument for thinking that people having multiple social identities might weaken stratification is based on the idea that increasingly widespread intragroup conflict might somehow replace intergroup conflict. Large divisions in society would fracture into many smaller divisions, and social strata would be less well defined. But this argument abstracts from how social power operates in a socially stratified world under the dominance of individualistic social ontologies. It is not the case, then, that intergroup conflict gives way to or is replaced by intragroup conflict. Rather the multiplication of social identities in a stratified world expands the scope for group conflict by adding intragroup conflict to existing intergroup conflict.

Notice that the analysis developed here addresses circumstances in which only one social group identity is stigmatized at a time. But the more common state of affairs is where stigmatization devalues multiple social identities simultaneously, as for example when women of color are 
targeted on both gender and racial grounds. How does this multiple-target form of stigmatization then affect individual mobility in a stratified world? On the argument above, when stigmatization affects how individuals weigh their social identities, they must consider how they prioritize who they see themselves as being 'like.' But distancing oneself from a set of stigmatized social identities is surely more difficult than distancing oneself from a single social identity since it is more difficult to see oneself as 'like' others who are 'unlike' oneself in multiple ways. This accordingly only adds force to the individualist scarcity logic representation of mobility opportunities, and the implication is again that social stratification is reinforced rather than weakened in an intersectional world. We might say that the degrees of freedom for stigmatizers are increased in a world that recognizes that people have multiple social identities. Ironically, then, social recognition of diversity can be employed to reinforce social stratification when it is coupled with individualist social ontologies.

\section{Social economic policy for a stratified world}

A socially stratified society is ethically objectionable and economically inefficient. It violates widely held ethical norms of fairness and respect for persons by perpetuating intergroup inequalities in well-being. Most individuals' level of lifetime achievement is constrained by social characteristics they inherit by accident of birth, while a minority enjoys advantages which exceed their level of achievement. Economic production falls below potential, since skill resources are used inefficiently by a systematic mismatching of tasks and abilities, so that overall level of well-being is lower as well. It follows that eradicating or even just reducing social stratification is both ethically and economically desirable. At the same time, it would be hard to deny that the obstacles to doing so are significant. Nonetheless, the analysis in this paper suggests two main policy strategies.

First, if we say that barriers to individuals' cross-strata movement are an important cause of social stratification, and we believe that upward mobility would be sought by individuals were these barriers reduced, then we basically seek to create conditions in which people are able to order and weight their social identities as they wish rather than as others find to their advantage. In the analysis here, stigmatization of social identities is a key means by which barriers to mobility are maintained for most people, while giving the appearance that barriers to mobility do not exist by creating opportunities for a few. Thus, since stigma is delivered through well-known means discrimination, social arrangements which penalize individuals by social identity, expressions of 
prejudice, identity-based abuse, etc. - these practices should be legally proscribed and ethically condemned. The effect of this would presumably be that social strata would become more socially heterogeneous. Higher social strata would then be less dominated by esteemed clusters of social identities and lower social strata less dominated by devalued clusters.

Second, the policy above does not address economic stratification per se where this involves those on higher social strata enjoying higher average well-being than those on lower strata. While reducing stigmatization practices could increase mobility for some individuals, in a stratified world most individuals on lower strata would still suffer resource disadvantages limiting their capacity to pursue mobility (as for example in cross-generational escape from poverty). Even in a world where stigma is curtailed, then, most individuals would still be unlikely to ascend hierarchical skill ladders unless they are somehow able to make up the skill deficits their social strata systematically produce. This means that fully addressing stratification as both social and economic in nature depends on transforming the basis on which people acquire and develop the skills employed in economic production. Thus as a counterpart to a social mobility policy it would be necessary that there be financial resource transfers, education and training, and the reorganization of the rewards from participation in production that offset this economic disadvantage - essentially a program of reparations aimed at redressing the injustice of systematic social inequality (Darity, 2009).

Note, finally, that these two types of policies work so as to increase the discretion people would be able to exercise in determining how they order and rank their social identities. Thus on the whole people would exhibit less socially determined path-dependence in their personal identities, and personal identities would be more variable and perhaps even less stable over time. This may sound undesirable, but emphasis should fall on the principle of self-determination rather than instability. The identity analysis used in this paper makes personal identity both socially and self-constructed. The social dimension concerns the way in which social statistical processes operate to define social groups by classifying people according to characteristics they share with other people. This classification process treats people as exclusively representative agents of social groups. In contrast, individual mobility makes people less classifiable as social group representative agents, as higher mobility rates undermine the standard social statistical identity construction process. The implication is that social construction of personal identity would then play a smaller role and that the self-construction of personal identity would play a larger role. The arguments above for reducing social stratification have ethical and economic grounds, but identity analysis adds to them a further argument for reducing stratification which rests on the desirability of greater individual 
self-determination of personal identity, where personal identity is a matter of one's chosen social group affiliations.

\section{References}

Akerlof, George and Rachel Kranton (2000) "Economics and Identity," Quarterly Journal of Economics 115: 715-753.

Archer, Margaret (2000) Being Human: The Problem of Agency, Cambridge: Cambridge University Press.

Becker, Gary (1957) The Economics of Discrimination, Chicago: The University of Chicago Press.

Becker, Gary (1996) Accounting for Tastes, Cambridge, MA: Harvard University Press.

Bénabou, Roland and Jean Tirole (2003) "Intrinsic and Extrinsic Motivation," Review of Economic Studies, 70: 489-520.

Blumer, Herbert (1958) "Race Prejudice as a Sense of Group Position," Pacific Sociological Review 1 (1): 3-7.

Bowles, Samuel (1998) “Endogenous Preferences: The Cultural Consequences of Markets and Other Economic Institutions," Journal of Economic Literature 36 (1): 75-111.

Branscombe, Nyla, Michael Schmitt, and Richard Harvey (1999) “Perceiving pervasive discrimination among African Americans: Implications for group identification and well-being," Journal of Personality and Social Psychology 77: 135-49.

Brewer, Marilynn and Wendi Gardner (1996) "Who is this 'we'? Levels of collective identity and self representations," Journal of Personality and Social Psychology 71: 83-93.

Crenshaw, Kimberlé (1989) "Demarginalizing the Intersection of Race and Sex: A Black Feminist Critique of Antidiscrimination Doctrine, Feminist Theory, and Antiracist Politics," University of Chicago Legal Forum 139-67.

Darity, William, Jr. (2003) “Will the Poor Always be with Us?” Review of Social Economy 61: 471-7. 
Darity, William, Jr. (2005) “Stratification Economics: The Role of Intergroup Inequality,” Journal of Economics and Finance 29 (2): 144-153.

Darity, William, Jr. (2009) "Stratification Economics: Context Versus Culture and the Reparations Controversy," Kansas Law Review 57: 795-811.

Darity, William, Jr. and Ashwini Deshpande (2003) Boundaries of Clan and Color: Transnational Comparisons of Inter-Group Disparity, London: Routledge.

Darity, William Jr., Patrick Mason, and James Stewart (2006) “The economics of identity: The origin and persistence of racial identity norms," Journal of Economic Behavior and Organization 60: 283305.

Darity, William, Jr., Patrick Mason, and James Stewart (2011) “Stratification Economics: Economics and Social Identity," American Economic Association Annual Meetings.

Ellemers, Naomi, Ad van Knippenberg, and Henk Wilke (1990) "The influence of permeability of Group Boundaries and Stability of Group Status on Strategies of Individual Mobility and Social Change," British Journal of Social Psychology 29: 233-46.

Ellemers, Naomi, Russell Spears, and Bertjan Doosje (2002) “Self and Social Identity,” Annual Review of Psychology 53: 161-86.

Frank, Reanne, Ilana Redstone Akresh, and Bo Lu (2010) “Latino Immigrants and the U.S. Racial Order: How and Where Do They Fit In?” American Sociological Review 75(2): 378-401.

Goffman, Erving (1963) Stigma: Notes on the Management of a Spoiled Identity, New York: PrenticeHall.

Goldsmith, Arthur, Darrick Hamilton, and William Darity Jr. (2006) "Shades of Discrimination: Skin Tone and Wages," American Economic Review 96 (2): 242-5.

Haslam, S. Alexander (2004) Psychology in Organizations, 2nd edition, London: Sage; first edition 2001.

Hogg, Michael, Deborah Terry, and Katherine White (1995) "A Tale of Two Theories: A Critical Comparison of Identity Theory with Social Identity Theory," Social Psychology Quarterly, 58: 255269. 
Jetten, Jolanda and Nyla Branscombe (2009) “Minority-Group Identification: Responses to Discrimination When Group Membership is Controllable," in Coping with Minority Status: Responses to Exclusion and Inclusion, Fabrizio Butera and John M. Levine, eds., New York: Cambridge University Press.

Lawson, Tony (1999) “Feminism, Realism, and Universalism,” Feminist Economics 5 (2): 25-59.

Major, Brenda and Laurie T. O’Brien (2005) “The Social Psychology of Stigma," Annual Review of Psychology 56: 393-421.

Mason, Patrick (2007) “Intergenerational Mobility and Interracial Inequality" The Return to Family Values," Industrial Relations 46 (11): 51-80.

Meyers, Diana (2000) “Intersectional Identity and the Authentic Self?” in C. Mackenzie and N. Stoljar, eds., Relational Autonomy: Feminist Perspectives on Autonomy, Agency, and the Social Self, Oxford: Oxford University Press: 151-180.

Samuels, Warren J. (1964a) “The Classical Theory of Economic Policy: Non-Legal Social Control (I),” Southern Economic Journal 31: 1-20.

Samuels, Warren J. (1964b) “The Classical Theory of Economic Policy: Non-Legal Social Control (II)," Southern Economic Journal 31: 87-100.

Steele, Claude (1997) "A Threat in the Air: How Stereotypes Shape Intellectual Identity and Performance," American Psychologist 52: 613-629.

Stets, Jan and Peter Burke (2000) "Identity theory and social identity theory," Social Psychological Quarterly 63: 283-295.

Stewart, James (2008a) “Africana Studies and Economics: In Search of a New Progressive Partnership," Journal of Black Studies 38 (5): 495-805.

Stewart, James (2008b) “Stratification Economics," International Encyclopedia of the Social Sciences, 2nd ed., W. Darity, ed., Detroit: Macmillan Reference USA: 530-1. 
Tajfel, Henri, Michael Billig, Robert Bundy, and Claude Flament (1971) "Social Categorization and Intergroup Behavior," European Journal of Social Psychology 1: 149-178.

Thoits, Peggy, and Lauren Virshup (1997) “Me’s and We's: Forms and Functions of Social Identities," In R. Ashmore and L. Jussim, eds., Self and Identity: Fundamental Issues, vol. 1, Oxford: Oxford University Press: 106-33.

Turner, John (1975) “Social Comparison and Social Identity," European Journal of Social Psychology 5: 5-34. 